\title{
Tough guys or sensitive guys? Disentangling the role of examiner sex on patient pain reports
}

\author{
Jacob M Vigil PhD, Joe Alcock MD
}

\begin{abstract}
JM Vigil, J Alcock. Tough guys or sensitive guys? Disentangling the role of examiner sex on patient pain reports. Pain Res Manag 2014;19(1):e9-e12.
\end{abstract}

BACKGROUND: Experimental and clinical pain studies are conflicting regarding whether individuals report heightened or dampened pain sensitivity in the presence of other men or women.

OBJECTIVES: In the present preliminary study, two small medical record reviews of patients admitted for emergency care were conducted to examine the possibility that patients may report differential pain intensity to male and female health care examiners. The study also sought to determine whether these effects are moderated by and, thus, only detectable by examining patients at different pain (debilitation) levels.

METHODS: Pain intensity scores were extracted from two medical record reviews of patients admitted for emergency care $(n=64$ and $n=135$, respectively). Pain intensity was measured using an 11-point numerical scale during standard triage assessments and the sex of the examiner was recorded. RESULTS: Mean pain scores reported to male and female emergency staff did not differ in either set of medical records. However, when patients were split between low and high pain levels, male patients reported higher pain scores to male practitioners when experiencing relatively low pain levels, and both male and female patients reported higher pain scores to female practitioners when experiencing relatively high pain levels.

DISCUSSION: The statistical magnitudes of these effects were large, suggesting that this phenomenon may be a pervasive feature in clinical settings and experimental pain studies.

CONCLUSION: These preliminary findings warrant larger-scale investigations of social contextual influences on patient pain reports, which are necessary for creating more standardized protocols for reliably assessing and treating patient pain experiences.

Key Words: Communication; Health disparities; Interpersonal; Pain intensity; Patient care

\section{Durs à cuire ou gars sensibles? Démêler le rôle du sexe de l'examinateur sur les déclarations de douleur des patients}

HISTORIQUE : Les études sur la douleur expérimentale et la douleur clinique sont conflictuelles selon que les individus déclarent une sensibilité à la douleur accrue ou atténuée à des hommes ou des femmes.

OBJECTIFS : Dans la présente étude préliminaire, les chercheurs ont procédé à deux petites analyses de dossiers de patients admis en soins d'urgence pour examiner la possibilité que les patients déclarent des intensités de douleur différentes aux examinateurs de sexe masculin et féminin. Létude visait également à déterminer si ces effets étaient modérés par différents niveaux de douleur (dégradation) et donc décelables seulement à l'examen des patients à ces différents niveaux de douleur.

MÉTHODOLOGIE : Les chercheurs ont extrait les indices d'intensité de la douleur de deux analyses de dossiers de patients admis en soins d'urgence ( $\mathrm{n}=64$ et $\mathrm{n}=135$, respectivement). Ils ont mesuré l'intensité de la douleur d'après une échelle numérique de 11 points pendant le tri standard. Le sexe de l'examinateur était consigné.

RÉSULTATS : Les indices moyens de douleur indiqués au personnel d'urgence de sexe masculin et féminin ne différaient pas dans les deux séries de dossiers. Cependant, lorsque les patients étaient répartis entre une faible intensité et une forte intensité de douleur, les patients de sexe masculin déclaraient des indices de douleur plus élevés aux praticiens lorsqu'ils souffraient d'un niveau de douleur relativement bénin, et tant les patients de sexe masculin que de sexe féminin déclaraient des niveaux de douleur plus élevés de sexe féminin lorsqu'ils ressentaient un niveau de douleur relativement élevé.

EXPOSÉ : Ces effets avaient une magnitude statistique importante, ce qui laisse supposer que ce phénomène peut être une caractéristique omniprésente dans les études expérimentales et cliniques de la douleur.

CONCLUSION : Ces résultats préliminaires justifient des recherches à plus vaste échelle sur les influences du contexte social sur les déclarations de douleur des patients, qui sont nécessaires pour créer des protocoles plus normalisés en vue d'évaluer et de traiter de manière plus fiable les expériences de douleur des patients.

partners (eg, family, significant other) that are most likely to provide solicitous reactions toward the individual experiencing pain (5-7). Given that, on average, women naturally demonstrate higher levels of parental investment and pain-empathizing behaviours than men (4,8-12), individuals, and especially women, are predicted to demonstrate greater pain sensitivity (eg, hyperalgesia) in the immediate presence of other women than in the presence of men (7).

The impact of the presence of women on the momentary pain intensity levels of men appears to be more dynamic. Our laboratory and others have found that, in men only, the real or simulated presence of female researchers or other female strangers during an experimental pain test (eg, cold pressor, ischemic) results in hypoalgesia (Vigil, unpublished data; Vigil, Rowell, Alcock, Maestes, unpublished data; 4,13,14). Other research has demonstrated that this hypoalgesic effect is linearly related to the absolute number of female strangers in the room during the pain task (4). Thus, it appears that, among healthy young men, the presence of female strangers produces a hypoalgesic effect, although the opposite pattern (hyperalgesia in the presence of a female researchers) has also been reported $(1,2)$. levels of felt pain in the immediate presence of the types of relationship

University of New Mexico, Albuquerque, New Mexico, USA

Correspondence: Dr Jacob M Vigil, Department of Psychology, University of New Mexico, 1 University of New Mexico, MSC03 2220,

Albuquerque, New Mexico 87131-1161, USA. Telephone 505-277-0374, fax 505-277-1394, e-mail vigilj@unm.edu 


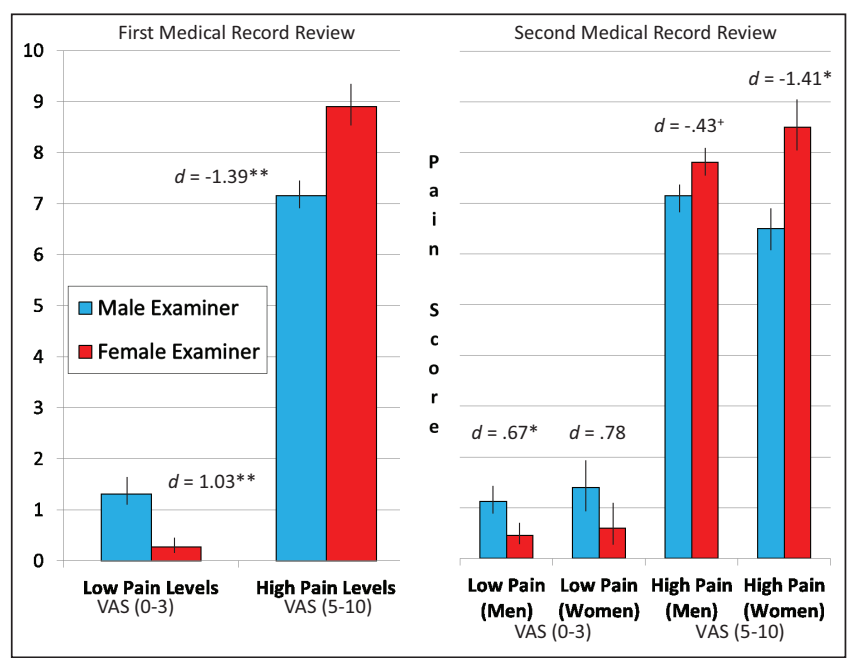

Figure 1) Patients report differential pain levels to male and female practitioners, depending on the relative pain level of the patient. The low pain condition consists of patients who reported pain scores on an 11-point visual analogue scale (VAS) from 0 to 3, and the high pain condition consists of patients who reported scores from 5 to 10. The first medical record review shows findings from predominantly male patients. The second review shows findings from a different set of medical records of male and female patients examined separately. Effect sizes are calculated with Cohen's d mean difference/mean SD. $+P<0.10, * P<0.05, * * P<0.01$

Clinical studies, however, show that solicitous spousal responses are associated with increased pain behaviours $(15,16)$, and that men, in particular, tend to report greater debilitating pain when they cohabitate with a spouse than when they live alone (Vigil, Pendleton, Coulombe, Vowles, Alcock, Smith, unpublished data). In other words, experimental and clinical pain studies are mixed on whether men report heightened or dampened pain sensitivity in the immediate presence of women. We believe that it is possible to interpret these seemingly discrepant findings from the social-signalling perspective that momentary pain intensity partly functions for demonstrating vulnerability and, ultimately, trustworthiness trait impressions to intimate confidantes and other audience members with characteristics, such as female sex, that signal the probability of providing empathy to the individual experiencing pain $(7,8,17)$. Therefore, the biological fitness costs and benefits of demonstrating heightened or lessened vulnerability to women should theoretically be contingent on implicit social expectations and other factors such as the momentary state or level of debilitation (ie, degree of pain severity) of the individual experiencing pain $(4-8,18)$. Because, on average, women naturally express higher levels of pain empathizing than men (eg, rating higher severity of others' pain $[4,7]$ ), women effectively serve as both an ecological and likely resource for consolation and caregiving for both sexes, as well as a potential reproductive partner for men. Men tend to use empowerment gestures (eg, concealed pain behaviours) to attract prospective mating partners $(9,10,12)$, whereas they use vulnerability gestures, including explicated pain behaviours, to elicit solicitous responses from more established and intimate social partners (eg, female kin) in times of need (ie, when the individual is physically debilitated $[7,8,17]$ ).

One may, therefore, expect that individuals, particularly men, facultatively experience varying pain intensity levels in the immediate presence of a male versus a female practitioner, and the directions of the differences depend on the relative state of debilitation (eg, pain intensity level) of the individual. If this phenomenon exists, it may be undetectable by comparing mean pain levels that patients report to male or to female examiners directly, and may only be observable by comparing patients who are at broadly distinct pain intensity levels. We conducted two preliminary medical record reviews of patients admitted for treatment in an urban emergency department to examine these possibilities.

\section{METHODS}

The data consist of pain scores that were obtained during standard triage assessments in the emergency department at the New Mexico VA Health Care System (Albuquerque, New Mexico, USA). All the patients were veterans and the pain scores were reported to medical examiners (predominantly registered nurses) using a numerical pain scale (visual analogue scale [VAS] 0 to 10 , where 0 indicates no pain and 10 indicates the worst pain imaginable). All patients presenting for emergency care receive a pain score as part of initial triage regardless of presenting complaint. Patients in the present analysis were not limited to any specific set of diagnoses. The first set of medical records consisted of nonrandomly selected patients originally (independent of the current study) flagged for review as part of standard quality assurance procedures ( $n=66$; $95 \%$ males, $61 \%$ male examiners); the age of the patients was not recorded as part of this medical record review. A second set of medical records was reviewed among a larger number of randomly selected patients 21 to 58 years of age $(n=140$; mean age 42.7 years, $81 \%$ males, $46 \%$ male examiners). Only information from the patients' initial visits to the emergency room was used.

\section{Data analyses}

The mean $( \pm S D)$ values of the pain scores from the two sets of medical records were $4.21 \pm 3.60$ and $5.02 \pm 3.46$, respectively, and the frequency distribution of the pain scores in the two sets of medical records was bimodal (median $=4.5 ;$ range $=10$; skewness $=0.20$, standard error $=0.30$, kurtosis $=-1.37$, standard error $=0.58$; and median $=6$, range $=10$, skewness values $=-0.25$, standard error $=$ 0.21 , kurtosis $=-1.36$, standard error $=0.41$, respectively). In accordance with the bimodal nature of the data, patients were separated into two broad group categories according to whether they reported pain levels between 0 and 3 (assigned to the 'low' pain condition), or whether they reported pain scores between 5 and 10 (assigned to the 'high' pain condition). This cutoff point was determined based on anecdotal observations that patients with a pain score $<4$ of 10 are not typically administered aggressive analgesic treatment during their health care visit. Patients with a VAS score of 4 were not included in the analyses to more clearly separate patient pain reporting across low and high pain levels, and because scores of 4 of 10 were the least frequent (two and five patients were excluded from the analyses from the first and second medical record reviews, respectively). Patients with pain scores of 0 out of 10 were included in the analyses because of the subjective and undefined nature of the term 'pain' and, thus, a pain score of 0 could imply different degrees of felt discomfort to different individuals. Fisher's exact test showed that the proportion of male to female examiners did not differ for patients in either pain condition for either set of medical records ( $\mathrm{P}=0.20$ and $\mathrm{P}=0.72$, respectively). For both sets of medical records, a between-subject ANOVA was used to examine the pain scores of patients who were assessed by either a male or a female examiner in each of the low and high pain conditions; independent-samples $t$ tests were used to compare group differences and effect sizes pertaining to group comparisons were estimated using Cohen's d (mean difference/mean SD [19]). The larger sample size in the second medical record review enabled an examination of potential group differences for male and female patients, separately.

\section{RESULTS}

Independent samples $t$ tests showed that the mean pain intensity scores reported to male and female examiners did not differ in either set of medical records $(\mathrm{P}=0.43$ and $\mathrm{P}=0.95$, respectively). For the first set of medical records, a $2 \times 2$ (Examiner Sex $\times$ Patient Condition) ANOVA was used to examine whether patients report differential pain scores to male or female examiners in the low $(n=31)$ and high $(n=33)$ pain conditions. The analysis revealed a significant Examiner Sex $\times$ Patient Condition interaction term $(F[1,63]=21.34, P<0.001)$. As shown in Figure 1, robust and inverse group differences emerged for pain scores reported to male and female examiners in the low pain 
condition $(t[21]=21.27, \mathrm{P}=0.008)$ and in the high pain condition $(t[31]=-3.65, \mathrm{P}=0.001)$; patients reported higher pain scores to male examiners in the low pain condition, and they reported higher pain scores to female examiners in the high pain condition.

For the second set of medical records, a $2 \times 2$ (Examiner Sex $\times$ Patient Condition) ANOVA was first conducted among the combined sample of male and female patients. These analyses revealed a significant Examiner Sex $\times$ Patient Condition interaction term $(\mathrm{F}[1$, $131]=11.05, \mathrm{P}=0.001)$. This interaction was again due to patients reporting higher pain scores to male examiners in the low pain condition $(t[36]=2.43, \mathrm{P}=0.020, \mathrm{~d}=0.71)$, and they reported higher pain scores to female examiners in the high pain condition $(t[84]=-2.77$, $\mathrm{P}=0.007, \mathrm{~d}=-0.60)$.

A $2 \times 2$ (Examiner Sex $\times$ Patient Condition) ANOVA conducted separately for male $(n=113)$ and female patients $(n=27)$ revealed a significant Examiner Sex $\times$ Patient Condition interaction term for both male $(\mathrm{F}[1,105]=5.82, \mathrm{P}=0.018)$ and female patients $(\mathrm{F}[1,22]=7.29, \mathrm{P}=0.013)$. Independent samples $t$ tests showed that male patients reported higher pain scores to male examiners in the low pain condition $(t[37]=2.11, \mathrm{P}=0.042)$, and they showed a trend to report higher pain scores to female examiners in the high pain condition $(t[68]=1.80, \mathrm{P}=0.077)$. Female patients only showed the latter pattern of reporting higher pain to female examiners in the high pain condition $(t[14]=-2.83, \mathrm{P}=0.013)$; the examiner effect was not detectable for the low pain condition $(\mathrm{P}=0.252)$. As shown in Figure 1, the statistical magnitudes of the observed effect sizes were moderate to large for men in the low pain condition, and they were moderate for men and robust for women in the high pain condition.

To ensure that the effects were not due to differences between examiners across subjects, multilevel models in which subjects (level 1 units) were nested within examiners (level 2 units) were also examined. Calculation of the intraclass correlation showed that the proportion of variance in VAS ratings due to differences between examiners was negligible $(<0.01 \%$ for both male and female subjects). As expected, given these low intraclass correlations, estimating multilevel models did not change any of the conclusions, and the probing of the significant Examiner Sex $\times$ Pain Group interactions among both male and female subjects using an online tool (20) yielded the exact same pattern as that shown in Figure 1. Therefore, only the results from the parsimonious ANOVA model are shown here.

\section{DISCUSSION}

Here we show for the first time that emergency department patients report higher pain intensity levels to male practitioners when initial pain intensity is low, and emergency department patients report higher pain to female practitioners when initial pain intensity is high. The statistical magnitudes of these effects were substantially larger than those from typical nonpharmacological psychological (eg, biofeedback, hypnosis, cognitive-behavioural, acceptance therapy, placebo) interventions for acute pain intensity (21-24). We therefore believe that the influence of this interaction between examiner sex and patient condition on patient pain reports ('VigilAlcock Effect') is probably a pervasive feature in clinical and experimental settings.

These findings are interpretable from a social-signalling perspective, in which men tend to experience hypoalgesia in the presence of women when at mild pain levels and, thus, when males are relatively capable and may be implicitly motivated to respond to female strangers as prospective reproductive partners. Because human males tend to utilize empowerment gestures (eg, bragging, inflated confidence, flashy body movements) to attract potential mates $(9,10,12)$, it makes biological sense that men would express attenuated pain reports and other vulnerability behaviours to women under these conditions. This interpretation also accounts for the experimental finding that healthy young men experience hypoalgesia when they are exposed to relatively mild forms of noxious stimuli in the presence of unfamiliar females (Vigil, unpublished data, Vigil, Rowell, Alcock, Maestes, unpublished data; 4,13). Of particular importance in the current study, pain scores of 3 and lower may often be clinically insignificant and scores in this category are less likely than higher scores to trigger analgesic treatment in the emergency department.

In contrast, patients with relatively high pain levels are likely to have clinically relevant pain and significant medical, psychiatric or other distress. High pain levels may cause both men and women to respond to other women as sources of solicitude, consolation and medical intervention. Because women evolved the behavioural heuristic to express higher levels of pain-empathizing behaviours than men in general $(4,8-12)$, people may have coevolved the expressive heuristic to report amplified pain intensity in the immediate presence of females when the individual's biological prowess and/or social status is perceived to be, or actually is, compromised. There is also some preliminary support that patient treatment may be associated with the health provider's sex. Some research suggests that female nurses, for instance, may assign higher emergency index severity ratings (ie, lower triage scores) to emergency care patients than male nurses (Vigil and Alcock, unpublished data), and that female physicians are more likely than male physicians to prescribe higher doses of analgesics to underserved categories of patients such as ethnic minorities and other women $(25,26)$.

The predictive validity of these hypotheses is, of course, contingent on larger studies among more representative samples of health care patients and, thus, investigations that can circumvent the obvious and notable limitations of the current study. The small sample sizes of patients examined in the present medical record reviews were undoubtedly confounded by innumerable relevant medical, social and contextual factors that may moderate and even mediate the modulating influence of examiner characteristics on momentary pain behaviours (eg, verbal reports and nonverbal pain gestures) and affective components of pain. For example, it is possible that the observations are not independent and, thus, the effect of examiner's sex may be unduly influenced by additional characteristics of examiners (eg, age, personality), and larger studies that can account for these potential nested effects are, therefore, warranted (although see last paragraph of Results section). However, despite these limitations, the current preliminary study is significant for showing that the sex of health practitioners, which is a ubiquitous contextual factor during all health provider/patient interactions, may be a potential source of health disparities in patient assessments, which has broad implications for measuring and interpreting patient pain reports momentarily, across time points, and across patient populations and clinical settings. The current findings may also elucidate contextual factors that implicitly influence experimental pain results under otherwise controlled laboratory conditions. Further research investigating social contextual influences on pain reports is, therefore, necessary for creating more standardized protocols for reliably assessing and for treating patient pain experiences.

ACKNOWLEDGEMENTS: The authors have no financial or other conflicts of interest associated with this work to declare. Both authors have full access to all the data in the study and take responsibility for the integrity of the data and the accuracy of the data analysis. The authors thank Patrick Coulombe for assistance with some of the statistical analyses. This work was supported by the New Mexico VA Health Care System, (Albuquerque, New Mexico) and by a pilot grant from the Clinical and Translational Science Center at the University of New Mexico (Albuquerque, New Mexico).

\section{REFERENCES}

1. Gijsbergs K, Nicholson F. Experimental pain thresholds influenced by sex of experimenter. Percept Mot Skills 2005;101:803-7.

2. Kállai I, Barke A, Voss U. The effects of experimenter characteristics on pain reports in women and men. Pain 2004;112:142-7.

3. McClelland LE, McCubbin JA. Social influence and pain response in women and men. J Behav Med 2008;31:413-20.

4. Vigil JM, Coulombe P. Biological sex and audience affects pain intensity and observational coding of other people's pain behaviors. Pain 2011;152:2125-30. 
5. Cano A, Williams A. Social interaction in pain: Reinforcing pain behaviors or building intimacy? Pain 2010;149:9-11.

6. Craig KD. The social communication model of pain. Can Psych 2009;50:22-32.

7. Vigil JM. A socio-relational framework of sex differences in the expression of emotion. Behav Brain Sci 2009;32:375-90.

8. Vigil JM. The socio-relational framework of expressive behaviors as an integrative psychological paradigm. Behav Brain Sci 2009;32:408-28.

9. Buss DM. Evolutionary Psychology: The New Science of the Mind, 4th edn. Needham Heights: Allyn \& Bacon, 2011.

10. Geary DC. Male, Female: The Evolution of Human Sex Differences, 2nd edn. Washington, DC: American Psychological Association, 2010.

11. Geary DC, Byrd-Craven J, Hoard MK, Vigil J, Numtee C. Evolution and development of boys' social behavior. Dev Rev 2003;23:444-70.

12. Geary DC, Vigil J, Byrd-Craven J. The evolution of human mate choice. J Sex Res 2004;41:27-42.

13. Aslaksen PM, Myrbakk IN, Hoifodt RS, Flaten MA. The effect of experimenter gender on autonomic and subjective responses to pain stimuli. Pain 2007;129:260-8.

14. Levine FM, De Simone LL. The effects of experimenter gender on pain report in male and female subjects. Pain 1991;44:69-72.

15. Flor H, Kerns RD, Turk DC. The role of spouse reinforcement, perceived pain, and activity levels of chronic pain patients. J Psychosom Res 1987;31:251-9.

16. Romano JM, Jensen MP, Turner JA, Good AB, Hops H. Chronic pain patient-partner interactions: Further support for a behavioral model of chronic pain. Behav Ther 2000;31:415-40.
17. Vigil JM. Sex differences in affect behaviors, desired social responses, and accuracy at understanding the social desires of other people. Evol Psychol 2008;6:506-22.

18. Schiavenato M, Craig KD. Pain assessment as a social transaction beyond the "gold standard". Clin J Pain 2010;26:667-76.

19. Cohen J. Statistical Power Analysis for the Behavioral Sciences, 2nd edn. Hillsdale, New Jersey: Lawrence Erlbaum, 1988.

20. Preacher KJ, Curran PJ, Bauer DJ. Computational tools for probing interaction effects in multiple linear regression, multilevel modeling, and latent curve analysis. J Educat Behav Stat 2006;31:437-48.

21. Vowles KE, McNeil DW, Gross RT, et al. Effects of pain acceptance and pain control strategies on physical impairment in individuals with chronic low back pain. Behav Ther 2007;38:412-25.

22. Milling LS, Reardon JM, Carosella GM. Mediation and moderation of psychological pain treatments: Response expectancies and hypnotic suggestibility. J Consult Clin Psychol 2006;74:253-62.

23. Nestoriuc Y, Rief W, Martin A. Meta-analysis of biofeedback for tension-type headache: Efficacy, specificity, and treatment moderators. J Consult Clin Psychol 2008;76:379-96.

24. Wiechman Askay S, Patterson DR, Jenses MP, Sharar SR. A randomized controlled trial of hypnosis for burn wound care. Rehabilitation Psychol 2007;52:247-53.

25. Weisse CS, Sorum PC, Sanders KN, Syat BL. Do gender and race affect decisions about pain management? J Gen Internal Med 2001;16:211-7.

26. Weisse CS, Sorum PC, Dominguez RE. The influence of gender and race on physicians' pain management decisions. J Pain 2003;4:505-10. 


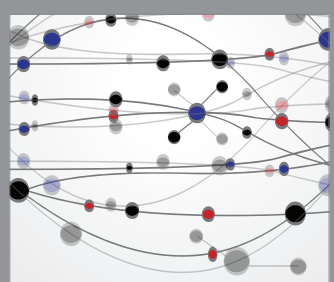

The Scientific World Journal
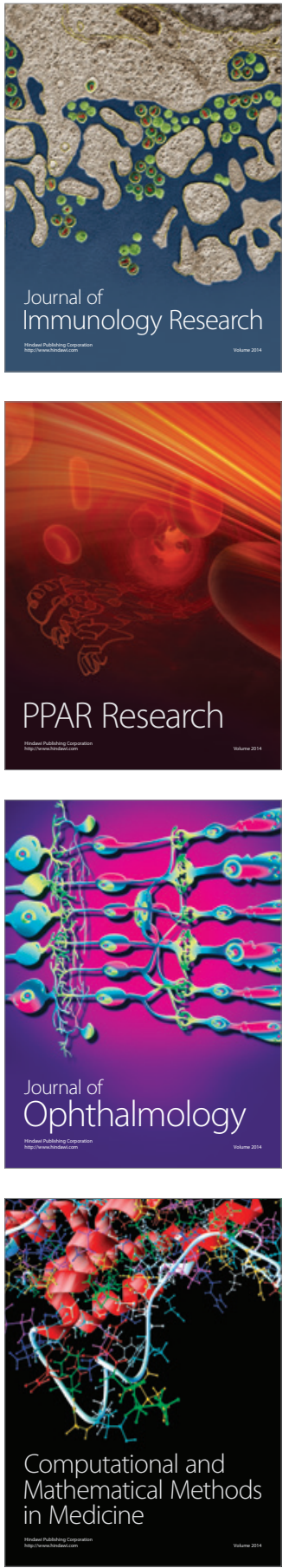

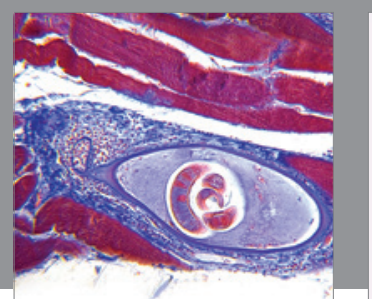

Gastroenterology Research and Practice

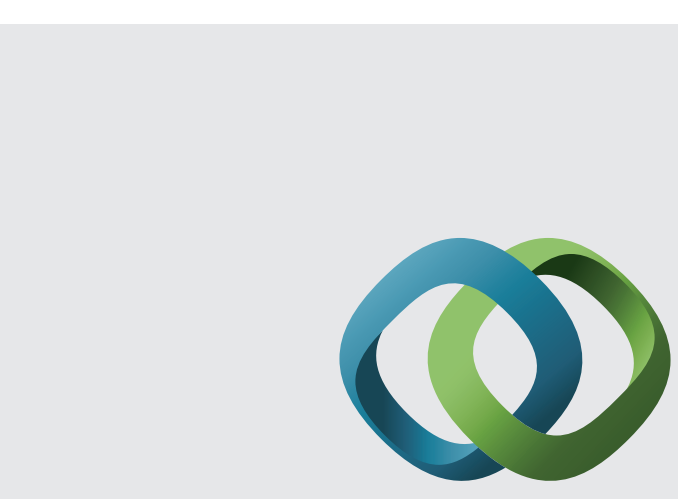

\section{Hindawi}

Submit your manuscripts at

http://www.hindawi.com
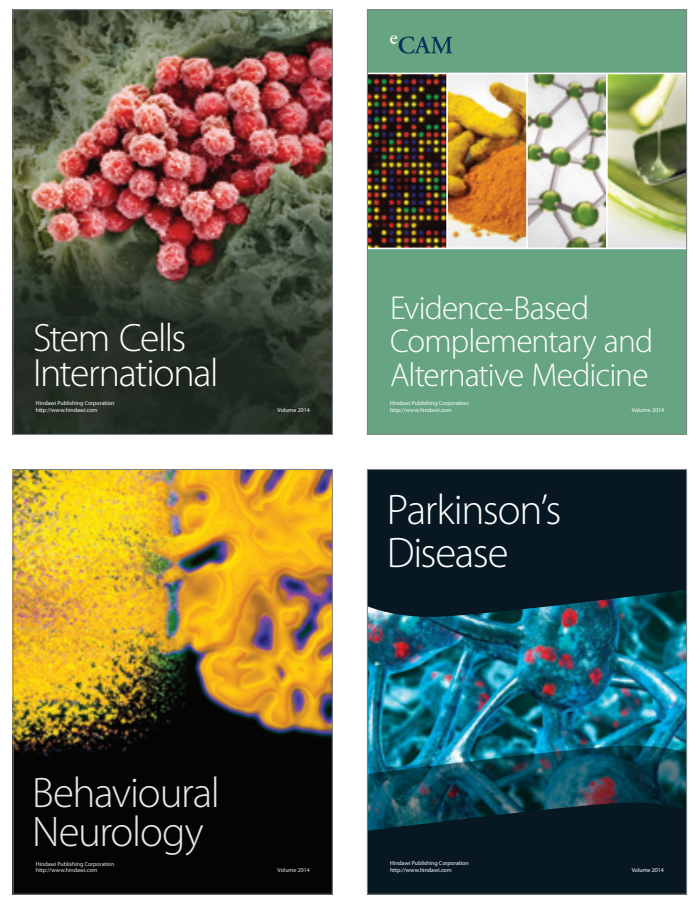
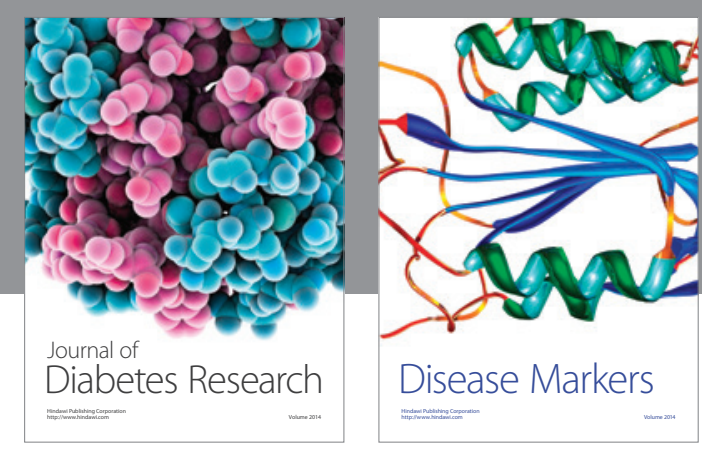

Disease Markers
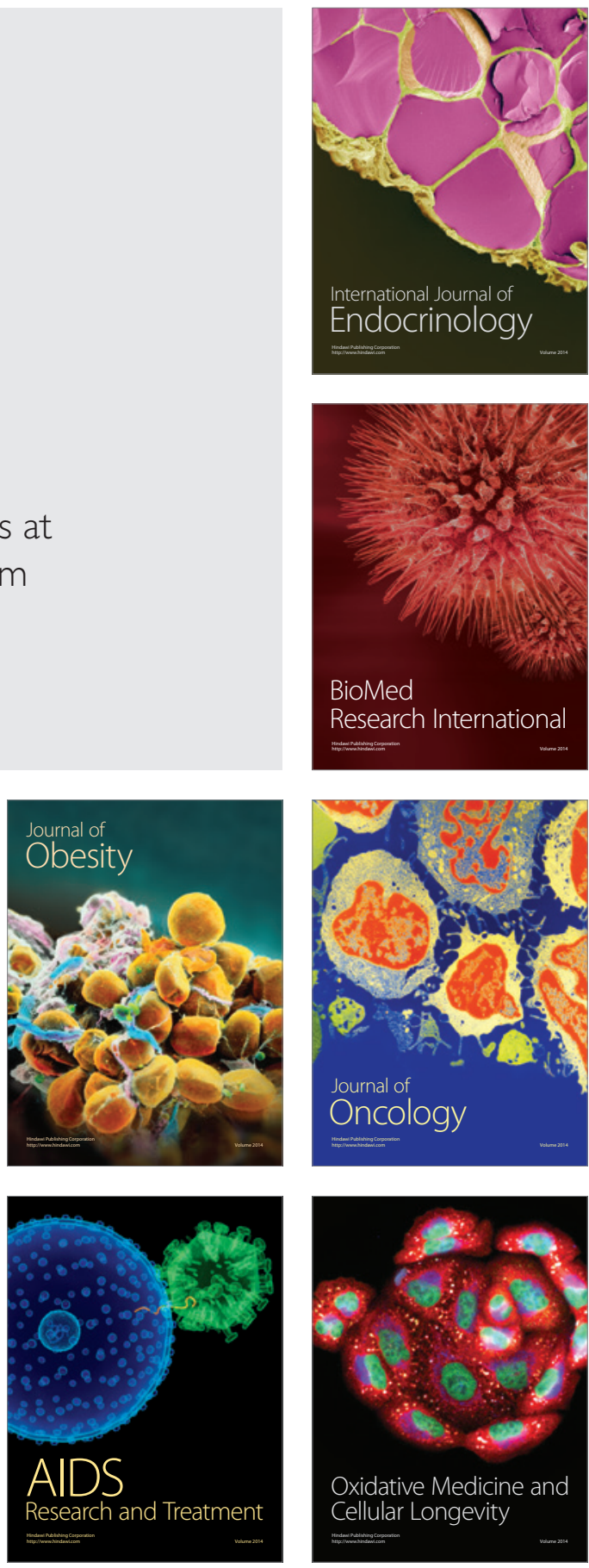